\title{
Phase Change Phenomena of Water under Depressurization State
}

\author{
T Watanabe'*, M Nakamura', K Tokunaga', \\ T Shiigi', H Ohta' and K Shimojima ${ }^{2}$ \\ 1. National Fisheries University, Japan \\ 2. Okinawa National College of Technology, Japan
}

\begin{abstract}
Latent heat of vaporization of water is very large compared to the latent heat of vaporization of other fluids. Therefore, when evaporation is promoted by decompressing, water lowers the temperature and freezes finally. We froze without heat exchange by exposure to vacuum the water using a vacuum pump. Despite violent boiling occurs, pressure in the vessel was going down. But, finally, at freeze process, the pressure in the vessel was increased. This pressure rise is caused by that amount of evaporation increases temporarily rapidly. The rapid increase in the amount of evaporation is due to the release of latent heat during freezing. This paper was focused on the pressure temperature change and mass change when the phase change of the water is switched to sublimation from the evaporation. This is likely to provide useful information when considering a phase-change model in a special state.
\end{abstract}

\section{INTRODUCTION}

It is very important in ensuring the safety of the cooling to know the behavior when the liquid was in vacuum. These studies have been made to subject the water to high temperature and high pressure that assumes the loss of coolant accident (LOCA) of nuclear power [1-5]. The authors conducted a study about the flash boiling of the cryogenic fluid and mentioned for the cryogenic fluid peculiar phenomenon [6-8]. On the other hand, the more we think about the nature and the environmental impact but is the safest to build a system using the familiar fluid, in order that there is a need to know the thermodynamic behavior in the various states. Water is also referred to as the most familiar and most specific substance, it is important to know the properties in different situations of water [9-12]. The authors focused on the evaporation amount changes during freezing of the water. When observing the elementary processes of the water at the time of freezing, difficult to control the cooling conditions, the effects of propagation speed and distribution makes it complicated the understanding of the phenomenon. Therefore, the authors control the pressure that has quick propagation speed and carried out experiments on decompression boiled freezes without heat supply. This decompression boiling, better known as the flashing phenomenon, has been studied extensively, in relation to loss-of-coolant accidents (LOCA) in nuclear reactors [13-15]. And research such as flash boiling spray characteristics in relation to combustion has been carried out. But, especially, reports on the amount of evaporation at the time of freezing have not been investigated sufficiently. The authors conducted experiments focusing on the evaporation amount during freezing and report the results.

${ }^{*}$ Corresponding Author: watanabe@fish-u.ac.jp 


\section{EXPERIMENTAL APPARATUS AND METHOD}

The experimental apparatus is illustrated schematically in Figure 1. The apparatus consists of a vacuum vessel, a cold trap, a vacuum pump, and measuring systems. Water is placed in a cup, the water entering the cup is placed in the vacuum vessel. The experiment will be initiated by the start-up of the vacuum pump. Evaporated water is trapped in the cold trap, gas without moisture is evacuated by a vacuum pump. The pressure was measured by using the Pirani gauge, the temperature of water was measured by using the copper-constantan thermocouple. Pressure and temperature data were logged and processed by a microcomputer. In these experiments, video images of the decompression behavior and pressure and temperature data were recorded.

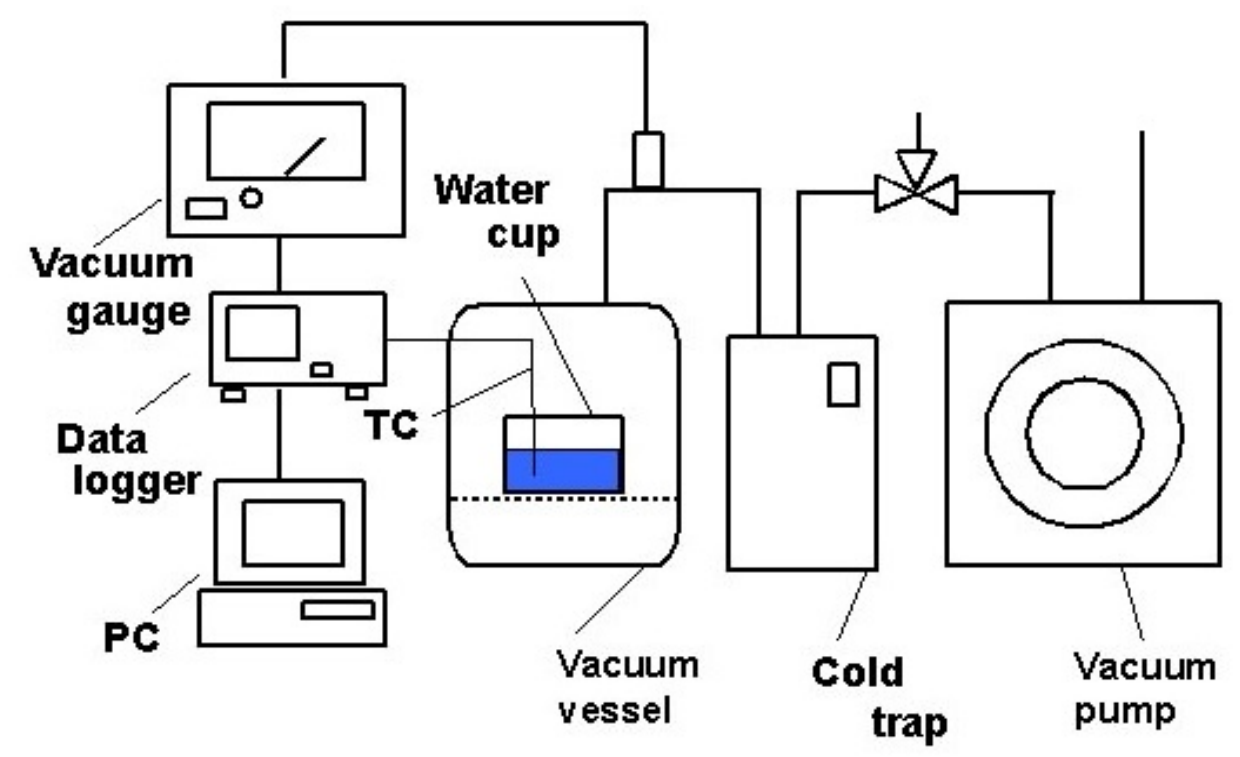

Figure 1: Experimental apparatus

\section{RESULTS AND DISCUSSIONS}

Photographs in Figure 2 show the visualized behavior of the water exposed to vacuum state. Figure 2(a) shows a state at the start of evacuation. Figure 2(b) shows the state after 23s, bubbles due to boiling in the vicinity of the thermocouple can be seen. In Figure 2(c), $t=26 \mathrm{~s}$, a lot of bubbles have occurred from the wall surface. Violent boiling occurs continuously throughout the cap in $\mathrm{t}=31 \mathrm{~s}$ in Figure 2(d). Then, Violent boiling gradually subside, boiling intermittently occur. And then finally boiling does not occur. In Figure 2(e), phase change is only on the surface evaporation. After the elapse approximately two minutes, water suddenly froze (see in Figure 2(f)). 


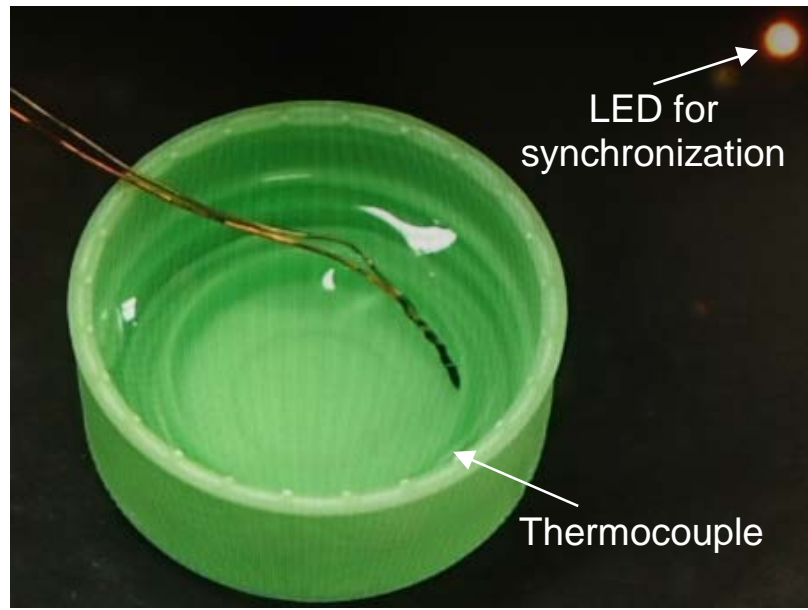

(a) $t=0 s$

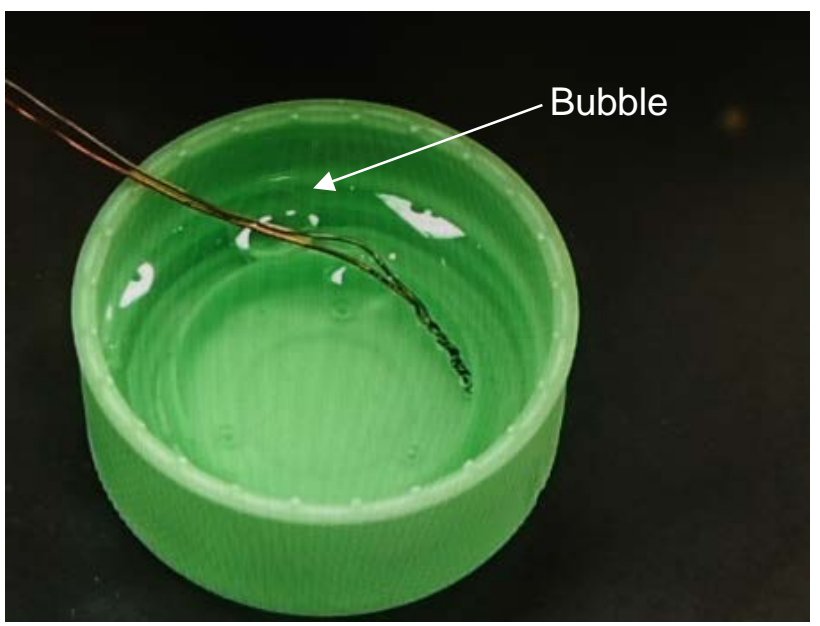

(b) $t=23 s$

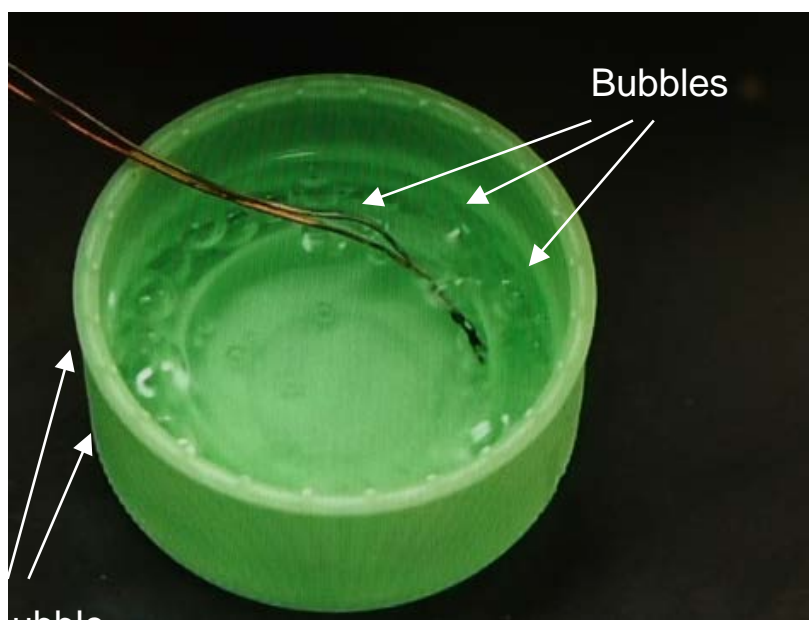

(c) $t=26 s$ 


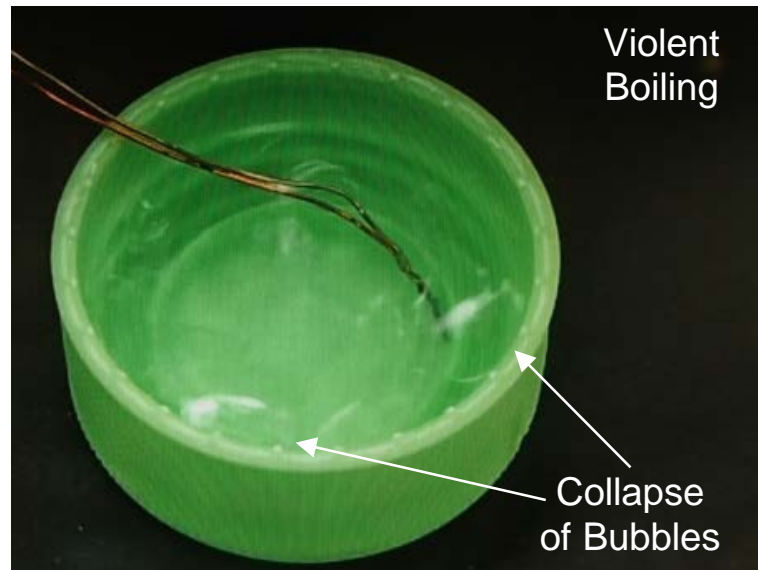

(d) $t=31 \mathrm{~s}$

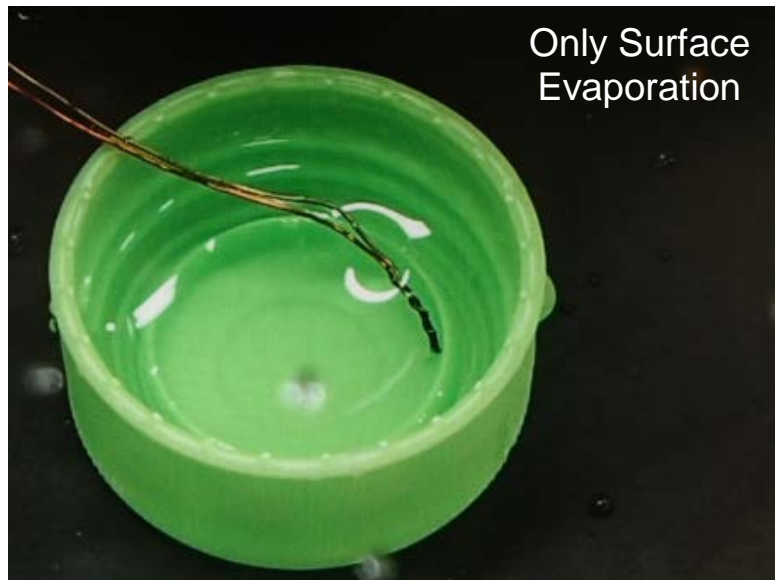

(e) $t=63 \mathrm{~s}$

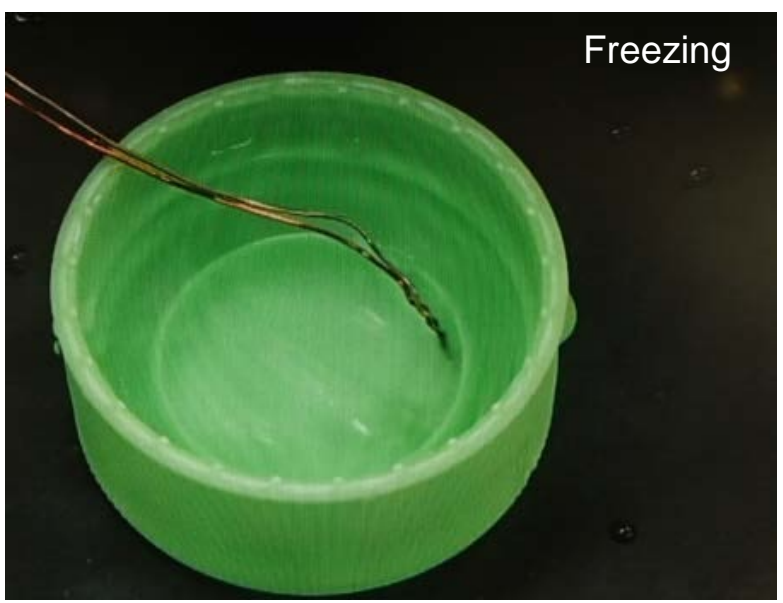

(f) $t=195 \mathrm{~s}$

Figure 2: Photographs of water aspect under decompression 
Figure 3 shows that the pressure change in the vacuum vessel and the change in temperature of the water. In this figure, green line shows the synchronization signal between photographs and pressure, temperature time history. Both pressure and temperature decrease and jump up like a pulse in the end. By comparison with the visualization results, when boiling occurs, temperature drops sharply, and pressure drop becomes gentle. This is because the amount of evaporation by boiling increases. Then, a rapid rise in temperature and pressure rises at the moment when the freeze occurs. At this time, the heat source is not present, and, because they are in a vacuum state, it may be considered that there is no heat penetration from the outside. Possible heat source is only the latent heat released during freezing. By the release of heat, the surface temperature of the ice is increased, the evaporation is promoted, and the pressure increases.

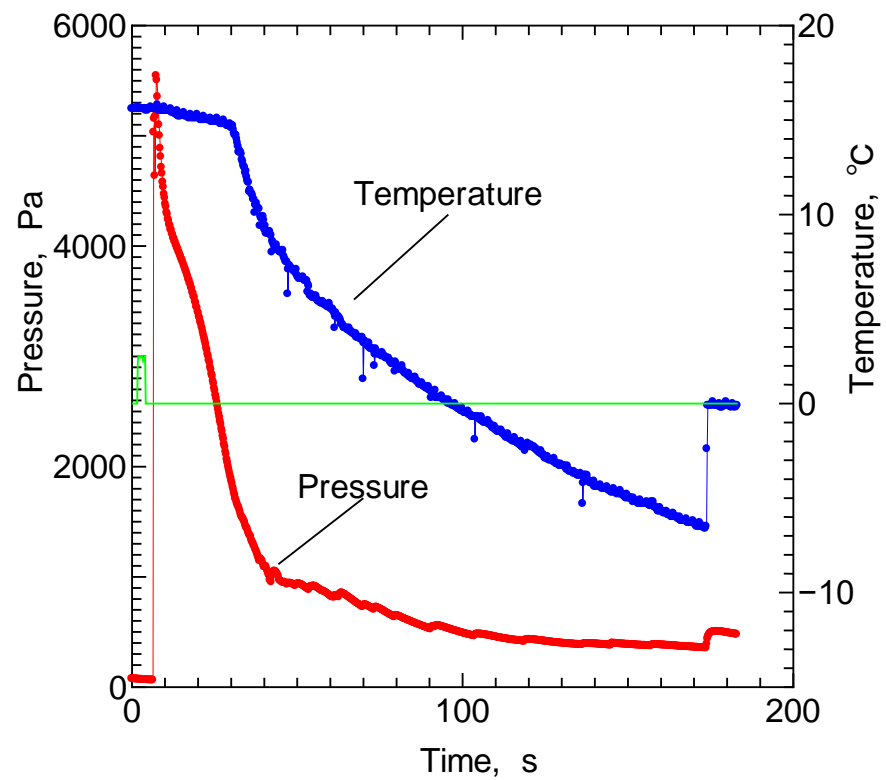

Figure 3: Pressure-time history and temperature-time history

It is shown that the results of experiments conducted by changing the initial mass of water in Figure 4. This figure shows the pressure change of each initial mass. Since the pressure rise is a sign of freezing, accordingly mass is increased, the time until freezing it can be seen that longer. Relationship in between the pressure increase amount and the initial mass due to freezing is not observed.

Figure 5 shows the temperature change of each initial mass. As well as changes in pressure, in accordance with mass increases, it can be seen that the time until the frozen longer. In addition, the timing of the pressure rise, and the temperature rise is consistent. However, the temperature rise amount due to freezing is not much different, is about $10^{\circ} \mathrm{C}$. Coincidentally, reaching the temperature is about $0{ }^{\circ} \mathrm{C}$ is the freezing temperature of water at atmospheric pressure. 


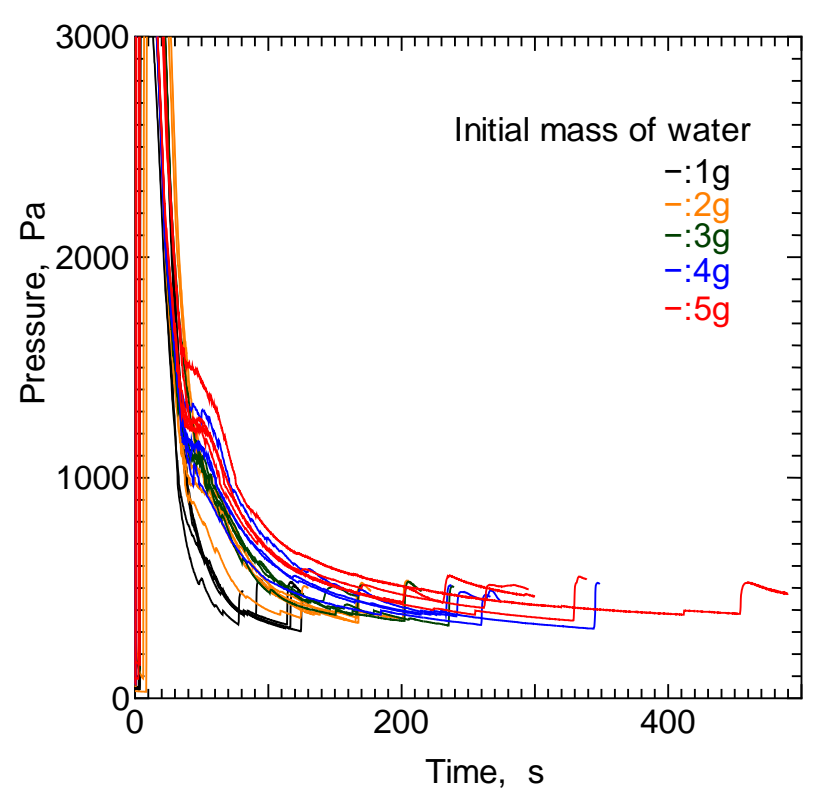

Figure 4: Temperature-time histories in several initial masses

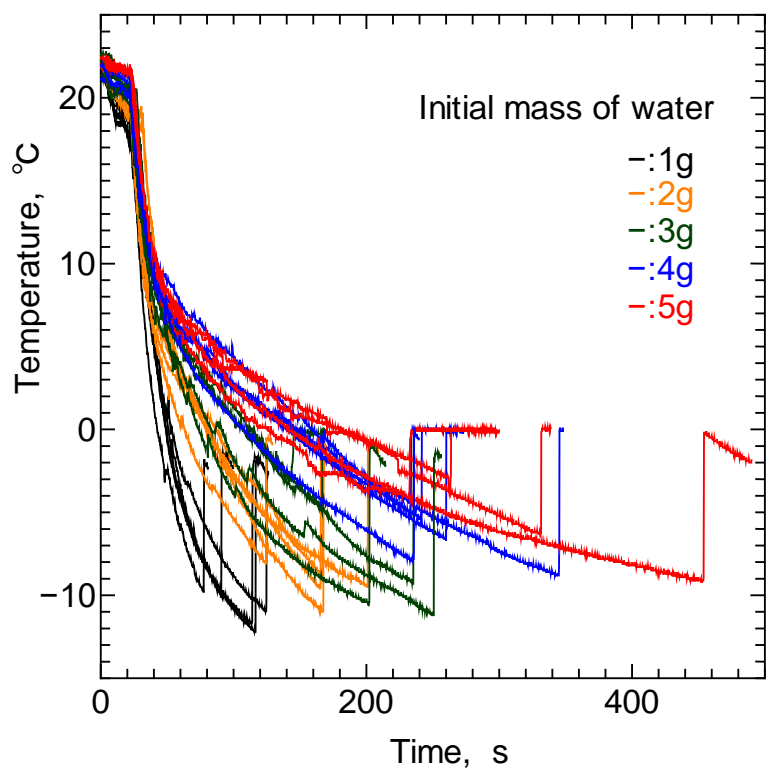

Figure 5: Temperature-time histories in several initial masses 
As already mentioned with respect to Figure 2, phase change in decompression freezing of water is changed boiling, surface evaporation, and freeze. The pressure continues to fall and rises at the time of freezing in the end. Therefore, we conducted experiments focusing on the amount of evaporation under each phase change. With memorizing the timing at which the phase change is change, we measured the residual mass of water at different timings under the same conditions. Decrease in the mass of water during every phase change was calculated by taking the difference residual mass of water at different timing. Figure 6 shows the decrease in the mass of water under each phase change. The horizontal axis shows the phase change scene. Decrease in the mass of water during boiling is plotted between after boiling and before boiling. The amount of decrease in the mass of water during surface evaporation before freezing is plotted between before freezing and after boiling. The amount of decrease in the mass of water during freezing is plotted between after freezing and before freezing. The amount of decrease in the mass of water increases with increasing initial mass of water during every phase change. As a matter of course, the amount of decrease in the mass of water during boiling is the largest. It is also important to remember that the amount of decrease in the mass of water during freezing is the larger than that during surface evaporation. As the elapsed time of the phase change, surface evaporation time is relatively long and freezing time is a moment. Rapid evaporation that occurs at the time of freezing is considered to have a very large instantaneous force. It is considered that this phenomenon occurs in the freeze cracking of the piping system.

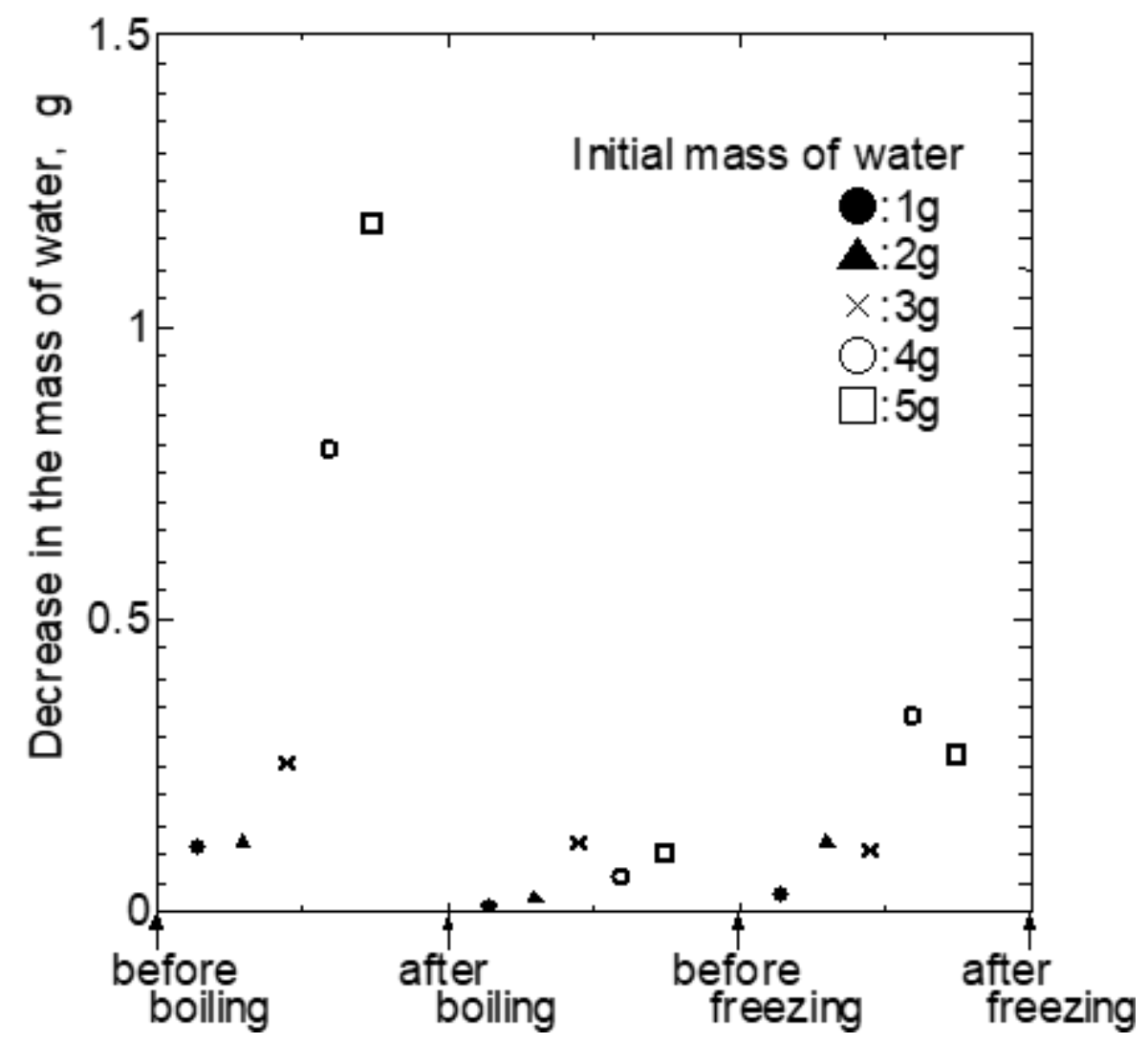

Figure 6: The mass of evaporation in boiling and in freezing 


\section{CONClusions}

Experiments have been carried out to examine the freezing phenomena of water under decompression. The conclusion can be summarized as follows.

(1) In decompression state, the water violently boils, and eventually freezes. At this time of freezing, although water does not boil, pressure rises with a rising temperature.

(2) Evaporation (gasification) during freezing is activated by discharged latent heat, the amount of mass of evaporation (gasification) is large enough to jump the pressure in the vacuum vessel.

\section{ACKNOWLEDGMENTS}

The authors express their sincere thanks to Mr. S. Uchida and Mr. K. Kobayashi at National Fisheries University for their help to this study. This work was supported by JSPS KAKENHI Grant Number JP19K06200.

\section{REFERENCES}

[1] Edwards, A. R. and O'Brien, T. P., 1970, "Studies of Phenomena Connected with the Depressurization of Water Reactors", J.Br. Nucl. Energy Soc., Vol.9, pp.125-135.

[2] Lienhard, J.H., Alamgir, Md. and Trela, M., 1978, "Early Response of Hot Water to Sudden Release from High Pressure", ASME Journal of Heat Transfer, Vol.100, No.3, pp.473-495.

[3] Alamgir, Md., Kan, C.Y. and Lienhard, J.H., 1980, "An Experimental Study of the Rapid Depressurization of Hot Water", Trans. ASME Journal of Heat Transfer, Vol.102, No.3, pp.433-438.

[4] Guler. M., Hannemann, R. J. and Sallet, D. W., 1979, "Unsteady Two-Phase Blowlowdown of a Flashing Liquid from a Finite Reservoir", Two-Phase, Heat \& Mass Transf., Vol.2, Hemisphere, pp.781-795.

[5] Alamgir,Md. and Lienhard,J.H., 1981, "Correlation of Pressure Undershoot During HotWater Depressurization", ASME Journal of Heat Transfer, Vol.103, pp.52-55.

[6] Watanabe, T., Hanaoka, Y. and Tokura, I., 1995, "Flashing Phenomena of Liquid Nitrogen in a Pressure Vessel", Trans. JSME, (in Japanese), Vol.61, No.585, pp.18491854.

[7] Yokoyama, S., Hanaoka, Y., Tokura, I. and Watanabe, T., 1992, "A Study of Liquid Nitrogen Flashing under Rapid Depressurization", Proc. 2nd JSME-KSME Thermal Engng. Conf., Vol.3, pp.321-326.

[8] Watanabe, T., Hanaoka, Y. and Tokura, I., 1998, "Flashing Phenomena of Liquid Nitrogen in a Pressure Vessel: Part 2: Mist formation and Behavior of the Liquid Surface in the Early Depressurization Process", Heat Trans. Japanese Research, Vol.27, No.5, pp.327-335.

[9] Plunket, T.L. and Scull, T.D., 1994, "Effects of Depressurization of Space Modules on Condensing Heat Exchangers", SAE Transactions Journal of AEROSPACE, Vol.103, Section 1, pp.1689-1696.

[10] Kowalczyk, W., Hartmann, C. and Delgado, A., 2003, "Freezing and thawing at the high hydrostatic pressure conditions - modeling and numerical simulation ", Proc. Appl. Math. Mech., Vol.3, pp.388-389. 
[11] Kulisiewicz, L., Kowalczyk, W., Baars, A. and Delgado, A., 2007, "Visualization of pressure-shift freezing and thawing of concentrated aqueous sucrose solutions", Int. Journal of High Pressure Research, Vol.27, No.2, pp.291-297.

[12] Ivashniov, O. E. and Ivashneva, M. N., 2016, "Vapor explosion under hot water depressurization flow", Journal of Fluid Mechanics, Vol.812, pp.65-128.

[13] Polanco, G., Holdo, A. and Munday, G., 2009, "Mass flow determination in flashing openings", Int. Journal of Multiphysics, Vol.3, No.4, pp.401-406.

[14] Haque, E.E.U. and Hampson, P.R., 2014, "Modelling Phase Change in a 3D Thermal Transient Analysis", Int. Journal of Multiphysics, Vol.8, No.1, pp.49-67.

[15] Messahel, R., Cohen, B., Moatamedi, M, Boudlal, A., Souli, M. and Aquelet, N., 2015, "Numerical and experimental investigations of water hammers in nuclear industry", Int. Journal of Multiphysics, Vol.9, No.1, pp.21-36. 
388 